\title{
Expression of multidrug resistance protein P-glycoprotein in correlation with markers of hypoxia (HIF-1 $\alpha$, EPO, EPO-R) in invasive breast cancer with metastasis to lymph nodes
}

\author{
Anna M. Badowska-Kozakiewicz ${ }^{1}$, Maria Sobol ${ }^{1}$, Janusz Patera ${ }^{2}$
}

${ }^{1}$ Department of Human Biophysics and Physiology, Medical University of Warsaw, Warsaw, Poland

2Department of Pathomorphology, Military Institute of Health Services, Warsaw, Poland

Submitted: 30 January 2016

Accepted: 21 September 2016

Arch Med Sci 2017; 13, 6: 1303-1314

DOI: $10.5114 /$ aoms.2016.62723

Copyright @ 2016 Termedia \& Banach

\section{Abstract}

Introduction: Overexpression of the mdr-1 gene is the earliest discovered mechanism of multidrug resistance, which is associated with P-glycoprotein (P-gp) - a cell membrane protein responsible for the efflux of drugs of various structures out of cancer cells. Although the expression of P-glycoprotein has been demonstrated in many cancer types, its relation to markers of hypoxia such as HIF-1 $\alpha$, EPO-R or EPO in invasive breast cancer is not well established. The aim of this research was to analyze the co-expression of P-glycoprotein and the markers of tissue hypoxia HIF-1 $\alpha$, EPO, and EPO-R by immunohistochemistry in invasive breast cancer classified according to the presence of steroid receptors and the HER2 receptors.

Material and methods: Tissue samples were collected from 58 patients with the diagnosis of invasive breast cancer with lymph node metastases. The expression of P-gp, HIF-1 $\alpha$, EPO-R and EPO was determined by immunohistochemistry.

Results: Of all the invasive breast cancers with lymph node metastases, $15.5 \%$ expressed P-gp in cell membrane and tumor blood vessels. In our research, there was a significant positive correlation between HER2-positive tumors that did not express steroid receptors (ER-/PR-/HER2+), and P-gp expression ( $p=0.049, r=0.105)$. Moreover, there was a significant positive correlation between EPO expression and P-gp $(p<0.001, r=0.474)$, and between HIF- $1 \alpha$ expression and P-gp $(p=0.00475, r=0.371)$.

Conclusions: We found that HIF- $1 \alpha$ and EPO expression is significantly associated with P-gp expression in invasive breast cancer with lymph node metastases. An important result of our study is the demonstration of a correlation between P-gp expression and patients with HER2-positive breast tumors that do not express steroid receptors.

Key words: P-glycoprotein, markers of hypoxia, invasive breast cancers with lymph node metastases.

\section{Introduction}

Because of very active cell proliferation, cancer tumors have a fast rate of growth. As the tumor grows, its cells are increasingly susceptible to oxygen deficiency, because of an increased demand and inadequate

\author{
Corresponding author: \\ Anna M. Badowska- \\ Kozakiewicz MD \\ Department \\ of Human Biophysics \\ and Physiology \\ Medical University of Warsaw \\ 5 Chałubińskiego St \\ 02-004 Warsaw, Poland \\ Phone: +48 502276536 \\ E-mail: \\ abadowska@wum.edu.pl
}


supply [1, 2]. This results from the low number of blood vessels that supply the tumor. In response to such unfavorable conditions, cancer cells produce factors that stimulate the development of new vessels and enable the necessary adaptation processes [2-4]. Uncontrolled proliferation of new tumor vessels leads to structural and functional defects, which results in the formation of pathological vessels that are not able to meet the tumor's demand. Consequently, a state of hypoxia ensues. Notably, a number of studies have confirmed that tumor hypoxia is associated with resistance to chemotherapy and radiation therapy, and can even stimulate metastasis. Cells that are located in the highly hypoxic regions of the tumor are not able to proliferate, and the dysfunctional vascular supply limits drug distribution, leading to poorer outcomes [4-6].

Some cancers have primary resistance to cytostatic drugs, while others develop drug resistance during chemotherapy in spite of initial susceptibility $[2,7]$.

Overexpression of the $m d r-1$ gene is the earliest discovered mechanism of multidrug resistance, which is associated with P-glycoprotein - a cell membrane protein that is responsible for the efflux of drugs of various structures out of cancer cells. P-glycoprotein belongs to a family of transport proteins termed the $A B C$ transporters. These proteins are found in different organisms, from bacteria to humans [6-9]. To date, 48 proteins of the $A B C$ family have been described, and are classified in 7 sub-classes (A-G) [6]. The fundamental function of the $A B C$ proteins is to protect the cell from potentially noxious substances such as xenobiotics or natural toxins. P-glycoprotein is the first and the best described protein from the $A B C$ family - it consists of two transmembrane domains, each comprising six alpha-helices. Additionally, there are two ATP-binding domains on the cytoplasmic end. Although there exist several hypotheses, the exact mechanism of action of P-glycoprotein has not been fully elucidated. It is thought that P-glycoprotein is an ATP-dependent pump whose function is to actively transport substances into the cell. P-glycoprotein removes toxic substances of exogenous origin, and takes part in hormone secretion. Moreover, P-glycoprotein plays other biological functions including the following: active efflux of drugs from cell cytoplasm; active transport of xenobiotics from the cytosolic to the external layer of the lipid bilayer, which enables further diffusion into the extracellular space; active transport of xenobiotics with chloride ions out of the cell; and active efflux of xenobiotics captured in the cell membrane [5]. Recent research suggests that the latter function seems the most plausible, since it postulates that drugs are recognized by P-glycoprotein already in the cell membrane and do not enter the cell at all. P-glycoprotein is coded by the $m d r-1$ gene. In the case of cancer cells, P-glycoprotein causes their resistance to chemotherapy, and its concentration correlates negatively with the expression of $m d r$ - 1 . Increased expression of P-glycoprotein has been demonstrated in patients with drug-resistant cancers such as ovarian cancer, colon cancer, breast cancer or gastric cancer [10-13].

Recent research on the mechanisms of multidrug resistance indicates that multidrug resistance can result from tissue hypoxia [5, 6, 14-16]. However, the correlation between P-gp expression and hypoxia markers (HIF-1, EPO, EPO-R) has not been clearly investigated in invasive breast cancers with lymph node metastases.

Therefore, the aim of this research was to analyze the co-expression of P-glycoprotein and markers of tissue hypoxia (HIF-1 $\alpha$, EPO and EPO-R) by immunohistochemistry in invasive breast cancer classified according to the presence of steroid receptors and the HER2 receptors.

\section{Material and methods}

\section{Patient selection and clinicopathological analysis}

We evaluated formalin-fixed, paraffin-embedded tissue blocks from 58 patients with a diagnosis of invasive breast cancer with lymph node metastases (the study was carried out as part of project NZME/PM42/15/15.

The mean age of the study participants was $59.9 \pm 12.3$ years (median: 58.5 years, range: $30-$ 79 years). Histological and immunohistochemical studies were performed at the Department of Pathology, Military Medical Institute in Warsaw. Tumor sections were fixed in 10\% phosphate buffered formalin. After 24-hour fixation, tissue samples were dehydrated in alcohols of gradually increasing concentrations - 50\%, 60\%, 70\%, $80 \%, 90 \%, 96 \%$ - followed by pure alcohol and xylene. Subsequently, they were embedded in paraffin blocks that were later cut into $4 \mu \mathrm{m}$-thick slices. Such prepared sections were then stained for diagnostic purposes with various methods. The tumors were classified and graded according to the WHO and the Nottingham modification of the Scarff-Bloom-Richardson systems. In routine $H \& E$ sections, the following evaluations were carried out: type of neoplasm (WHO classification), tumor grade including tubule formation, intensity of division as well as the degree of neoplastic cell differentiation and mitotic index, expressed as the mean number of mitotic figures in neoplastic cells counted in 10 fields of vision at a 400× magnification (surface field $0.17 \mathrm{~mm}^{2}$ ). 
Among 58 cases of invasive breast cancer with lymph node metastases, there were 50 (86.22\%) invasive ductal carcinomas of no special type (IDC-NST), 5 (8.62\%) metaplastic carcinomas, 2 (3.44\%) invasive lobular carcinomas and $1(1.72 \%)$ mixed ductal and lobular carcinoma. Regarding the histological grade of malignancy, the largest group of invasive breast cancer with lymph node metastases comprised grade 2 and grade 3 (43.1\%; 51.72\%) (G2 and G3) tumors. During the analysis of the pre-operative staging of the studied cancers, it was found that the largest group of invasive breast cancer tumors with lymph node metastases consisted of those assessed as T1 (37.9\%) and T2 (48.3\%). The lymph node status was also assessed during the study; N1 and N2 were found in $53.4 \%$ and $29.3 \%$ respectively (Table I).

\section{Immunohistochemical staining for steroid receptor and HER2 (ER, PR and HER2)}

For immunohistochemistry, paraffin sections attached to glass slides covered with $2 \%$ saline/ acetone solution (Sigma) and dried for $24 \mathrm{~h}$ at $42^{\circ} \mathrm{C}$ were used. Prior to the immunohistochemi- cal staining, sections were dewaxed by immersion in a series of alcohols of gradually decreasing concentrations followed by washing in distilled water. Subsequently, the sections were placed in a buffer solution of $\mathrm{pH} 9$ (Dako) in the case of estrogen receptors, or of $\mathrm{pH} 6$ (Dako) for all other antigens, followed by heat treatment in a $90^{\circ} \mathrm{C}$ water bath for $30 \mathrm{~min}$, in order to uncover the epitope. When antigen epitopes were revealed, sections were cooled for $20 \mathrm{~min}$. After washing twice with distilled water and incubating in 3\% hydrogen peroxide for $5 \mathrm{~min}$, the sections were washed with TBS buffer (Tris-Buffered Saline, Code: S1968, pH 7.6) (Sigma). The primary antibody was applied in an appropriate dilution and incubated in a moisture chamber for 60 minutes at room temperature. Specimens were subsequently washed in TBS buffer (Tris-Buffered Saline, Code: 1968, pH 7.6) (Sig$\mathrm{ma}$ ) for $10 \mathrm{~min}$. Appropriate monoclonal or polyclonal sets were used for each antibody in order to visualize the immunohistochemical reaction, followed by washing in TBS buffer (Tris-Buffered Saline, $\mathrm{pH}$ 7.6) (Sigma) and application of diaminobenzidine (DAB) (Substrate-Chromogen Solution) solution, prepared according to the manufactur-

Table I. Clinicopathological characteristics of invasive breast cancer with metastasis to lymph nodes

\begin{tabular}{|c|c|c|}
\hline \multirow[t]{2}{*}{ Parameter } & \multicolumn{2}{|c|}{$\begin{array}{l}\text { Number of patients with invasive breast cancer with } \\
\text { metastasis to lymph nodes (total = 58) } \\
\text { Age (mean } \pm \text { SD) } 59.9 \pm 12.3\end{array}$} \\
\hline & $N$ & $\%$ \\
\hline \multicolumn{3}{|l|}{ Histological type of invasive breast cancer: } \\
\hline Invasive ductal carcinoma of no special type (IDC-NST) & 50 & 86.22 \\
\hline Metaplastic carcinoma & 5 & 8.62 \\
\hline Invasive lobular carcinoma (ILC) & 2 & 3.44 \\
\hline Mixed ductal and lobular carcinoma & 1 & 1.72 \\
\hline \multicolumn{3}{|l|}{ Tumor stage $(\mathrm{pT})$ : } \\
\hline $\mathrm{T} 1$ & 22 & 37.9 \\
\hline $\mathrm{T} 2$ & 28 & 48.3 \\
\hline T3 & 2 & 3.44 \\
\hline $\mathrm{T} 4$ & 6 & 10.36 \\
\hline \multicolumn{3}{|l|}{ Nodal stage $(\mathrm{pN})$ : } \\
\hline N1 & 31 & 53.4 \\
\hline $\mathrm{N} 2$ & 17 & 29.3 \\
\hline N3 & 10 & 17.3 \\
\hline \multicolumn{3}{|l|}{ Tumor grade (G1-G3): } \\
\hline G1 & 3 & 5.18 \\
\hline $\mathrm{G} 2$ & 25 & 43.1 \\
\hline G3 & 30 & 51.72 \\
\hline
\end{tabular}


er's instructions, for $10 \mathrm{~min}$, in order to visualize the color of the reaction. Sections were inspected for color intensity, and subsequently washed in tap water, stained with Ehrlich's hematoxylin for 5 min, differentiated in $1 \%$ acid alcohol solution, and washed in tap water once again. Sections were then dehydrated in graded alcohol series of increasing concentrations, cleared in xylene and embedded in DPX mounting medium (Gurr ${ }^{\circledR}$ Co.).

The primary antibodies used in immunohistochemical studies were monoclonal antibodies specific for estrogen receptors (Monoclonal Mouse Anti-Human Estrogen Receptor $\alpha, 1$ : 50 dilution, Clone: 1D5, Code: IR654, Dako) and progesterone receptors (Monoclonal Mouse Anti-Human Progesterone Receptor, 1 : 400 dilution, Clone: PR636, Code: IR068, Dako), which were used in order to determine their expression. Immunohistochemistry was performed using EnVision-HRP (DakoCytomation) (EnVision + Dual Link System-HRP, DAB+, Code: K4065). Evaluation of immunohistochemical markers was performed by two pathologists as follows: ER and PR were categorized as negative (0\%) or low positive (1-10\%), whereas nuclear staining in $>10 \%$ of tumor cells was considered positive for $E R$ and $P R$.

HER2 expression was determined using HercepTest (Dako) (Code: K5204). It enabled detection of HER2 expression using a polyclonal antibody specific for this protein (Rb A-Hu HER2 - Rabbit Anti-Human HER2 Protein). HER2 results were determined based on the maximum area of staining intensity according to the manufacturer's instructions and the American Society of Clinical Oncology (ASCO)/College of American Pathologists (CAP) guidelines as follows: strong, circumferential membranous staining in $>30 \%$ of invasive carcinoma cells was graded $3+$; moderate, circumferential membranous staining in $\geq 10 \%$ of invasive tumor cells or strong, circumferential membranous staining in $\leq 30 \%$ of cells was designated as $2+$ staining; weak and incomplete membranous staining in invasive tumor cells was scored as 1+; and no staining was marked 0 . Specimens with 0 to $1+$ were regarded as negative and those with $3+$ were considered positive. Results identified as HER2 2+ were verified by fluorescence in situ hybridization (FISH). Positive and negative control preparations were previously determined.

\section{Immunohistochemical staining for HIF-1 $\alpha$, EPO, EPO-R and P-gp}

HIF-1 $\alpha$, EPO, EPO-R and P-gp localization on the tissue sections was performed using the avidin-biotin immunoperoxidase technique. Prior to the immunohistochemical staining, sections were dewaxed by immersion in a series of alcohols of gradually decreasing concentrations followed by washing in distilled water. Incubations were performed at room temperature $\left(20^{\circ} \mathrm{C}\right)$ in a humidified chamber. Antigen unmasking was performed by microwave heat treatment, with sodium citrate buffer $(\mathrm{pH} \mathrm{6)}$. The sections were heated twice at $95^{\circ} \mathrm{C}$ for $5 \mathrm{~min}$ in a standard microwave oven, and the slides allowed to cool down in the buffer for approximately $20 \mathrm{~min}$. The sections were then rinsed and washed twice in deionized water. The sections were incubated with $1 \%$ hydrogen peroxide in deionized water for 10 min to quench intrinsic endogenous peroxidase activity, followed by two 5-minute washes in phosphate-buffered saline (PBS) at $\mathrm{pH}$ 7.4. The sections were then incubated for $20 \mathrm{~min}$ in 1 to 3 drops of $5 \%$ normal goat serum.

Subsequently, the sections were incubated for $2 \mathrm{~h}$ at room temperature in a moist chamber with primary antibodies: mouse monoclonal anti-human HIF-1 $\alpha$ (1 : 50 dilution, Clone: 28b, sc:13515; Santa Cruz Biotechnology, Inc.), rabbit polyclonal anti-human EPO (1 : 100 dilution, Clone: H-162, Sc:7956; Santa Cruz Biotechnology, Inc.), rabbit polyclonal anti-human EPO-R (1 : 250 dilution, Clone: C-20, sc:695; Santa Cruz Biotechnology, Inc.) and mouse monoclonal anti-human P-gp (1 : 100 dilution, Clone: E-10, sc:390883; Santa Cruz Biotechnology, Inc.).

The sections were then rinsed and washed twice with PBS and they were incubated in 1 to 3 drops of prediluted biotinylated secondary antibody (ImmunoCruz Mouse ABC Staining System, Sc:2017; ImmunoCruz Rabbit ABC Staining System for visualization, sc:2018; ImmunoCruz Rabbit LSAB Staining System, sc:2051; ImmunoCruz Mouse LSAB Staining System, sc:2050 [Santa Cruz Biotechnology, Inc.]) for $30 \mathrm{~min}$, followed by two brief washes in PBS. The site of the immunoreaction was made visible by incubating the sections with 1 to 3 drops of horseradish peroxidase (HRP)-streptavidin complex (ImmunoCruz TM Staining System sc:2017, sc:2018, sc:2051 and sc:2050; Santa Cruz Biotechnology, Inc.), for 30 min followed by a brief wash with PBS, followed by incubation with 1 to 3 drops of $3^{\prime}, 3^{\prime}$-diaminobenzidine tetrahydrochloride (DAB). They were developed for 20 min until the desired stain intensity appeared. The sections were washed twice for 5 min each in de-ionized water. After that, sections were counterstained briefly for $10 \mathrm{~s}$ with hematoxylin. Sections were then dehydrated in graded alcohol series of increasing concentrations, cleared in xylene and embedded in DPX mounting medium (Gurr ${ }^{\oplus}$ Co.).

A total of 58 cases of invasive breast cancer with metastasis to lymph nodes were assessed for the expression of HIF-1 $\alpha$ (Monoclonal Mouse Anti-Human HIF-1 $\alpha$, Clone: 28b, sc:13515; Santa Cruz Biotechnology, Inc.). The visualization system 
ImmunoCruz Mouse ABC Staining System, sc:2017 (Santa Cruz Biotechnology, Inc.) was subsequently applied. Tumor-cell immunoreactivity was scored according to both the extent of nuclear staining (relative number of HIF-1 $\alpha$-positive cells) and the intensity of the reaction: [-] not detected; [+] $<1 \%$ positive cells; [+] $1-10 \%$ weakly to moderately stained cells; [++] 1-10\% intensively stained cells or $10-50 \%$ weakly stained cells; $[+++] 10-50 \%$ positive cells with moderate to marked staining; $[++++]>50 \%$ positive cells [14]. Positive controls consisted of HIF-1 $\alpha$ immunoreactive breast cancer tissues. Negative controls were prepared with the omission of primary antibodies.

Expression of erythropoietin (EPO) was also assessed in all of the studied invasive breast cancers using an appropriate antibody specific for the EPO antigen (Polyclonal Rabbit Anti-Human EPO, Clone: H-162, sc:7956; Santa Cruz Biotechnology, Inc.) and subsequent application of the ImmunoCruz Rabbit ABC Staining System for visualization, sc:2018 (Santa Cruz Biotechnology, Inc.). EPO staining results were scored according to the percentage of cytoplasmic positive cells as follows: $(-)$, < 10\%; (+), 10-20\%; (++), > 20\%. Moderate expression of EPO was defined as $>20 \%$ tumor cells with positive staining, whereas low expression was $<20 \%$ [15].

In all examined invasive breast cancers we also assessed the expression of erythropoietin receptor (EPO-R) using an appropriate antibody against EPO-R antigen (Polyclonal Rabbit AntiHuman EPO-R, Clone: C-20, sc:695; Santa Cruz Biotechnology, Inc.) and ImmunoCruz Rabbit LSAB Staining System, sc:2051 (Santa Cruz Biotechnology, Inc.) for visualization. EPO-R staining results were scored according to the percentage of membrane positive cells as follows: $(-)<10 \%$; (+), 10-20\%; (++) > 20\%. Moderate expression of EPO-R was defined as $>20 \%$ tumor cells with positive staining, whereas < $20 \%$ was considered low expression. The immunoexpression of EPO-R was located mainly within cell membranes, although in most cases also a granular cytoplasmic reaction was observed [15]. For EPO and EPO-R slides, adult kidneys were used as positive controls.

Fifty-eight cases of invasive breast cancer with metastases to lymph nodes were assessed for the expression of P-gp using a specific primary antibody (Monoclonal Mouse Anti-Human P-gp, Clone: E-10, sc:390883; Santa Cruz Biotechnology, Inc.), and subsequent application of the ImmunoCruz Mouse LSAB Staining System, sc:2050 (Santa Cruz Biotechnology, Inc.). P-gp expression was graded according to the percentage of stained tumor cells: (0\%) [-] none; (1-9\%) [+] weak; (10-69\%) [++] moderate; (70-100\%) [+++] strong [16].

\section{Statistical analysis}

All statistical analyses were performed with SPSS software v12.0. The chi-square $\left(\chi^{2}\right)$ test was used to assess the relationship between P-gp and the expression of steroid receptors, HER2, HIF- $1 \alpha$, $E P O, E P O-R$, the degree of histological malignancy, and clinical staging.

The Fisher exact test was used when the expected cell counts were less than 5 . The results were considered statistically significant if the $p$ value was less than $0.05(p<0.05)$. Spearman rank correlation was used to analyze the association. Yule's $\Phi$ and Cramér's $\vee$ tests were used to analyze the association.

Spearman's rank-order correlation is a nonparametric test. Spearman's correlation coefficient measures the strength of association between two ranked variables. Its value is between -1 and 1.

Cramér's $\vee$ test is a measure of association between two nominal variables. It gives a value between 0 and 1. Cramér's $V$ test is used as a posttest to determine the strength of association after $\chi^{2}$ has determined significance. Yule's $\Phi$ test is used to find a correlation in a $2 \times 2$ contingency table. The correlation coefficient gives a value between -1 and 1 .

\section{Results}

The mean age of the study participants was $59.9 \pm 12.3$ years (median: 58.5 years, range: $30-$ 79 years). In the pathological examination the following cancer types were found: invasive ductal carcinoma of no special type (IDC-NST; 86.22\%) (Figure 1), invasive lobular carcinoma (ILC; 3.44\%), metaplastic carcinoma (8.62\%), and mixed ductal and lobular carcinoma (1.72\%).

In this study, we observed and analyzed the expression and relationship of HIF-1 $\alpha$, EPO, EPO-R and P-gp in 58 specimens (invasive breast cancer with lymph node metastases) using immunohistochemistry (Figures 2 A-D). Of all the invasive

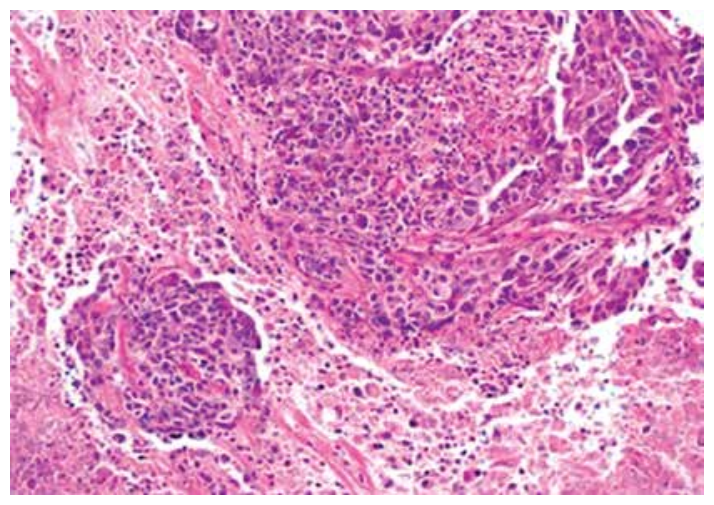

Figure 1. Histopathological image of invasive ductal carcinoma of no special type of breast cancer (IDCNST) (grade 3, H \& E, original magnification, 200x) 

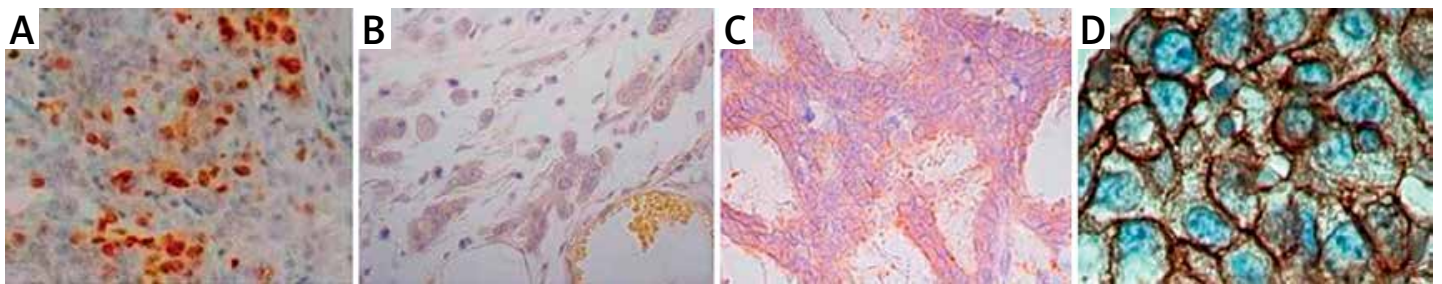

Figure 2. Immunohistochemical analysis of HIF-1 $\alpha$, EPO, EPO-R, P-gp expression in invasive breast cancers with lymph node metastases. Positive staining images for: A - HIF-1 $\alpha$, B - EPO, C - EPO-R, D - P-gp; A, B, C - original magnification, 200x; D - original magnification, 400×

breast cancers with lymph node metastases, $15.5 \%$ expressed P-gp in cell membrane and tumor blood vessels, and $84.5 \%$ did not express P-gp. The most frequent cancer type among tumors expressing P-gp was IDC-NST (13.8\%).

We evaluated the relationship between histological grade (G1-G3), tumor size (pT), the presence of lymph node metastases (pN1-N3), and $\mathrm{P}$-gp expression in cancer cells - no statistically significant associations were found $(p>0.05)$. Among invasive breast cancers with lymph node metastases that expressed P-gp, 55.5\% were graded at G3. P-gp expression was found most frequently in invasive breast cancers with lymph node metastases that were staged at pT1, pT2, and $\mathrm{pN} 1$ or pN2 (Table II).

Among the studied breast tumors, four basic immunohistochemical patterns were determined, as follows: PR+/ER+/HER2+ (22.4\%); PR-/ER-/ HER2+ (32.76\%); PR-/ER-/HER2- (12.07\%); PR+/ ER+/HER2- (32.76\%), with IDC-NST being the most common in each pattern (86.22\%).

P-gp expression in cancer cells or tumor blood vessels was found in $26.31 \%$ of ER+/PR+/HER2tumors, $15.4 \%$ of ER+/PR+/HER2+, $14.3 \%$ of ER-/ PR-/HER2- and $5.3 \%$ of ER-/PR-/HER2+ tumors, respectively.

In our research, there was a significant positive correlation between HER2-positive tumors that did not express steroid receptors (ER-/PR-/ HER2 + ), and P-gp expression ( $p=0.049, r=0.105$ ) (Table III). We found no correlation between HER2 positive/negative and P-gp expression ( $p=0.274$, $r=0.050$ ) (Table II).

Moreover, there was a significant positive correlation between EPO expression and P-gp ( $p<$ $0.001 ; r=0.474)$, and between HIF-1 $\alpha$ expression and P-gp $(p=0.00475, r=0.371)$. We found no correlation between EPO-R expression and P-gP $(p=0.059, r=0.272)$ (Table II).

In the case of P-gp-positive tumors, $55.6 \%$ of patients showed strong staining (70-100\%; "+++"), 33.3\% of patients showed moderate staining (10-69\%; "++") and $11.1 \%$ of patients showed weak staining (1-9\%; “+”).

In our research, we found no correlation between percentage of tumor cells stained for P-gp
(“+”, “++", “+++") and HIF-1, EPO, EPO-R, ER, PR, HER2 expression, or lymph node status (pN1-N3), but we found a correlation between percentage of tumor cells stained for P-gp and histological grade (G1-G3) ( $p=0.002, r=0.687)$ (Table IV). We found a correlation between percentage of tumor cells stained for P-gp and percentages of tumor cells stained for HIF-1 $\alpha(p=0.048, r=0.273)$ and EPO $(p=0.018, r=0.60)$. We found no correlation between percentage of tumor cells stained for P-gp and percentage of tumor cells stained for EPO-R $(p=0.10, r=0.553)$ (Table V).

\section{Discussion}

Treatment failure in breast cancer is still common, and therefore it is crucial to look into the issue of multidrug resistance, which in turn results from the activity of P-glycoprotein and tumor hypoxia $[1-3,7]$.

There are multiple reasons for treatment failure in cancer treatment, and the chemotherapeutics used to date do not always damage cancer cells. The limited susceptibility to treatment may be an inherent, biological feature of a given tumor or could result from multidrug resistance of cancer cells. Similarly, a defective structure of tumor blood vessels and increased intratumoral pressure, both hampering the penetration of drugs into cancer cells, could lead to limited susceptibility to chemotherapeutics. Moreover, even when the drug does target cancer cells, it is not certain that it will work effectively [4-6].

There are many immunohistochemical studies that have analyzed the relationship between the expression of P-glycoprotein in cancer and the efficacy of treatment. However, little is known about the possible relation between P-glycoprotein and the new prognostic and predictive markers. The relationship between P-gp expression and treatment outcomes has already been studied in patients with lung cancer, bladder cancer, ovarian cancer, and breast cancer [17-25].

Young et al. confirmed high expression of P-gp in small-cell (80\%) and non-small-cell lung cancer (100\%). Using RT-PCR, they determined P-gP expression in $25 \%$ and $43 \%$ of patients with these tumors, respectively [17]. Galimberti et al. 
Expression of multidrug resistance protein P-glycoprotein in correlation with markers of hypoxia (HIF-1 $\alpha$, EPO, EPO-R) in invasive breast cancer with metastasis to lymph nodes

Table II. Relationship between the expression P-glycoprotein and the expression HER2, EPO, HIF-1 $\alpha$, EPO-R and clinicopathological parameters of invasive breast cancer with metastasis to lymph nodes

\begin{tabular}{|c|c|c|c|c|}
\hline \multirow[t]{3}{*}{ Parameter } & \multicolumn{4}{|c|}{$\begin{array}{c}\text { Number of patients }(N=58)(\%) \\
\text { Age (years, mean } \pm \text { SD) } 59.9 \pm 12.3\end{array}$} \\
\hline & \multicolumn{4}{|c|}{ Expression of P-gp } \\
\hline & P-gp-positive & P-gp-negative & $P$-value* & $r$ \\
\hline \multicolumn{5}{|c|}{ Histological grade $(\mathrm{G})$ : } \\
\hline$\overline{\mathrm{G} 1}$ & $1(1.72)$ & $2(3.45)$ & 0.609 & $0.162^{\mathrm{a}}$ \\
\hline $\mathrm{G} 2$ & $3(5.16)$ & $22(37.93)$ & & \\
\hline G3 & $5(8.62)$ & $25(43.12)$ & & \\
\hline \multicolumn{5}{|c|}{ Tumor stage (pT): } \\
\hline T1 & $4(6.90)$ & $18(31.03)$ & 0.83 & $0.949^{\mathrm{a}}$ \\
\hline $\mathrm{T} 2$ & $5(8.62)$ & $23(39.65)$ & & \\
\hline T3 & $0(0)$ & $2(3.45)$ & & \\
\hline T4 & $0(0)$ & $6(10.35)$ & & \\
\hline \multicolumn{5}{|c|}{ Nodal stage $(\mathrm{pN})$ : } \\
\hline $\mathrm{N} 1$ & $5(8.62)$ & $26(44.83)$ & 0.275 & $0.215^{\mathrm{a}}$ \\
\hline N2 & $4(6.90)$ & $13(22.41)$ & & \\
\hline N3 & $0(0)$ & $10(17.24)$ & & \\
\hline \multicolumn{5}{|c|}{ Expression of HER2: } \\
\hline Positive & $3(5.18)$ & $29(50)$ & 0.274 & $0.050^{\mathrm{b}}$ \\
\hline Negative & $6(10.35)$ & $20(34.47)$ & & \\
\hline \multicolumn{5}{|c|}{ Expression of EPO: } \\
\hline Positive & $8(13.8)$ & $13(22.41)$ & $<0.001^{*}$ & $0.474^{b}$ \\
\hline Negative & $1(1.73)$ & $36(62.06)$ & & \\
\hline \multicolumn{5}{|c|}{ Expression of HIF-1 $\alpha$ : } \\
\hline Positive & $7(12.06)$ & $14(24.14)$ & $0.00475^{\star}$ & $0.371^{b}$ \\
\hline Negative & $2(3.45)$ & $35(60.35)$ & & \\
\hline \multicolumn{5}{|c|}{ Expression of EPO-R: } \\
\hline Positive & $6(10.34)$ & $15(25.9)$ & 0.059 & $0.272^{\mathrm{b}}$ \\
\hline Negative & $3(5.17)$ & 34 (58.59) & & \\
\hline
\end{tabular}

${ }^{*}$ Statistically significant results $p<0.005$; significant correlations are shown in bold. ${ }^{a}$ Cramér's $V$-test was used to analyze the association. 'Yule's $\Phi$ test was used analyze the association.

Table III. Relationship between basic immunohistochemical profile (ER/PR/HER2) and expression of P-gp in invasive breast cancer with metastasis to lymph nodes

\begin{tabular}{|c|c|c|c|c|c|}
\hline \multirow{2}{*}{$\begin{array}{l}\text { Immunohistochemistry - basal panel } \\
\text { for diagnosis of breast cancer }\end{array}$} & \multirow{2}{*}{$\begin{array}{c}\text { Frequency } \\
N=58\end{array}$} & \multicolumn{2}{|c|}{ Expression of P-gp } & \multirow[t]{2}{*}{$P$-value* } & \multirow[t]{2}{*}{$r$} \\
\hline & & Positive & Negative & & \\
\hline ER-/PR-/HER2- & 7 & 1 & 6 & 0.845 & $0.105^{c}$ \\
\hline $\mathrm{ER}+/ \mathrm{PR}+/ \mathrm{HER} 2+$ & 13 & 2 & 11 & 0.675 & \\
\hline ER-/PR-/HER2+ & 19 & 1 & 18 & $0.049^{\star}$ & \\
\hline $\mathrm{ER}+/ \mathrm{PR}+/ \mathrm{HER} 2-$ & 19 & 5 & 14 & 0.137 & \\
\hline
\end{tabular}

*Statistically significant results $p<0.05$; significant correlation is shown in bold. 'Spearman rank correlation was used to analyze the association. 
Table IV. Association between clinicopathologic variables (tumor grade and nodal stage), expression of HIF-1 $\alpha$, EPO, EPO-R, ER, PR, HER2 and P-glycoprotein expression

\begin{tabular}{|c|c|c|c|c|c|}
\hline \multirow{2}{*}{$\begin{array}{l}\text { Clinicopathologic } \\
\text { variables }\end{array}$} & \multicolumn{3}{|c|}{ Expression of P-gp } & \multirow[t]{2}{*}{$P$-value* } & \multirow[t]{2}{*}{$r$} \\
\hline & $\begin{array}{l}\text { Weak (percentage } \\
\text { of stained tumor } \\
\text { cells } 1-9 \% \text { ) }\end{array}$ & $\begin{array}{l}\text { Moderate (percentage } \\
\text { of stained tumor } \\
\text { cells } 10-69 \% \text { ) }\end{array}$ & $\begin{array}{l}\text { Strong (percentage } \\
\text { of stained tumor } \\
\text { cells } 70-100 \% \text { ) }\end{array}$ & & \\
\hline \multicolumn{6}{|c|}{ Tumor grade (G1-G3): } \\
\hline G1 & 1 & 0 & 0 & $0.002^{*}$ & $0.687^{a}$ \\
\hline G2 & 0 & 3 & 0 & & \\
\hline G3 & 0 & 0 & 5 & & \\
\hline \multicolumn{6}{|l|}{ Nodal stage $(\mathrm{pN})$ : } \\
\hline N1 & 1 & 1 & 3 & 0.487 & $0.283^{\mathrm{a}}$ \\
\hline N2 & 0 & 2 & 2 & & \\
\hline N3 & 0 & 0 & 0 & & \\
\hline \multicolumn{6}{|c|}{ Expression of HIF-1 $\alpha$ : } \\
\hline Positive & 1 & 3 & 3 & 0.583 & $0.5^{\mathrm{a}}$ \\
\hline Negative & 0 & 0 & 2 & & \\
\hline \multicolumn{6}{|l|}{ Expression of EPO: } \\
\hline Positive & 1 & 3 & 4 & 0.60 & $0.866^{a}$ \\
\hline Negative & 0 & 0 & 1 & & \\
\hline \multicolumn{6}{|c|}{ Expression of EPO-R: } \\
\hline Positive & 0 & 3 & 3 & 0.286 & $0.00^{\mathrm{a}}$ \\
\hline Negative & 1 & 0 & 2 & & \\
\hline \multicolumn{6}{|l|}{ Expression of ER: } \\
\hline Positive & 1 & 3 & 3 & 0.583 & $0.5^{\mathrm{a}}$ \\
\hline Negative & 0 & 0 & 2 & & \\
\hline \multicolumn{6}{|l|}{ Expression of PR: } \\
\hline Positive & 1 & 3 & 3 & 0.583 & $0.5^{\mathrm{a}}$ \\
\hline Negative & 0 & 0 & 2 & & \\
\hline \multicolumn{6}{|l|}{ Expression of HER2: } \\
\hline Positive & 0 & 0 & 3 & 0.286 & $0.00^{\mathrm{a}}$ \\
\hline Negative & 1 & 3 & 2 & & \\
\hline
\end{tabular}

*Statistically significant results $p<0.005$; significant correlation is shown in bold. ${ }^{a}$ Cramér's $V$ test was used to analyze the association.

found P-gp expression in $27 \%$ of patients with non-small-cell lung cancer [18]. Clifford et al., who studied P-gp expression in urinary bladder cancer, reported that P-gp was also expressed in normal bladder samples. In their study, P-gp was expressed rarely in poorly differentiated tumors, whereas in highly differentiated tumors the expression of P-gp was found in $27 \%$ of cases [19]. Nakagawa et al., in their immunohistochemical study of 33 patients with the diagnosis of urinary bladder cancer, reported that P-gp was expressed in $67 \%$ of patients before chemotherapy, and in
$14 \%$ after therapy. Moreover, they did not find any significant relationship between the expression of P-gp and treatment outcome [20]. Park et al. assessed the association between the expression of P-gp and the response to doxorubicin in 28 treatment-naive patients with urinary bladder cancer - no relationship was found between the level of P-gp expression and the efficacy of doxorubicin [21]. Joly et al. found that P-gp is expressed in a low proportion of ovarian cancer cells, which is associated with a lack of response towards P-gp inhibitors [22]. Similar studies have been carried 
Table V. Relationship between expression of HIF-1 $\alpha$, EPO, EPO-R and P-glycoprotein expression

\begin{tabular}{|c|c|c|c|c|c|}
\hline \multirow[t]{2}{*}{ Parameter } & \multicolumn{3}{|c|}{ Expression of P-gp } & \multirow[t]{2}{*}{$P$-value* } & \multirow[t]{2}{*}{$r$} \\
\hline & $\begin{array}{l}\text { Weak } \\
\text { (percentage } \\
\text { of stained tumor } \\
\text { cells 1-9\%) }\end{array}$ & $\begin{array}{l}\text { Moderate } \\
\text { (percentage } \\
\text { of stained tumor } \\
\text { cells } 10-69 \% \text { ) }\end{array}$ & $\begin{array}{l}\text { Strong } \\
\text { (percentage } \\
\text { of stained tumor } \\
\text { cells } 70-100 \% \text { ) }\end{array}$ & & \\
\hline \multicolumn{6}{|l|}{ Expression of HIF-1 $\alpha$ : } \\
\hline $\begin{array}{l}{[+]<1 \% \text { positive cells } / 1-10 \%} \\
\text { weakly to moderately stained } \\
\text { cells }\end{array}$ & 0 & 0 & 0 & $0.048^{*}$ & $0.273^{\mathrm{a}}$ \\
\hline $\begin{array}{l}{[+] 1-10 \% \text { intensively }} \\
\text { stained cells or } 10-50 \% \\
\text { weakly stained cells }\end{array}$ & 1 & 1 & 0 & & \\
\hline $\begin{array}{l}\text { [+++] } 10-50 \% \text { positive cells } \\
\text { with moderate to marked } \\
\text { staining }\end{array}$ & 0 & 0 & 5 & & \\
\hline$[++++]>50 \%$ positive cells & 0 & 0 & 0 & & \\
\hline Expression of EPO-R: & & & & 0.10 & $0.553^{\mathrm{a}}$ \\
\hline [+] 10-20\% positive cells & 1 & 2 & 0 & & \\
\hline$[++]>20 \%$ positive cells & 0 & 0 & 3 & & \\
\hline Expression of EPO: & & & & $0.018^{*}$ & $0.60^{\mathrm{a}}$ \\
\hline [+] 10-20\% positive cells & 1 & 2 & 0 & & \\
\hline$[++]>20 \%$ positive cells & 0 & 0 & 5 & & \\
\hline
\end{tabular}

*Statistically significant results $p<0.005$; significant correlations are shown in bold. ${ }^{a}$ Cramér's $V$ test was used to analyze the association.

out in breast cancer patients, and the relationship between the expression of P-gp and treatment outcomes has been assessed most commonly. However, little is known with regard to the association between P-gp and other diagnostic markers such as erythropoietin, erythropoietin receptor, and HIF- $1 \alpha$ that additionally characterize the biological features of the tumor and could have an impact on developing new treatment methods.

Decker et al. did not detect any significant relation between P-glycoprotein expression and response to chemotherapy in patients with breast cancer [26]. In contrast, Burger et al. reported a significant correlation between the expression of P-gp mRNA and treatment response in 59 patients with breast cancer [23]. Turkina et al. as well as Trock et al. found the expression of P-gp in $41 \%$ of patients with breast cancer $[24,25]$. This proportion reached $80 \%$ in the studies of Chung et al. and Chevillard et al. $[27,28]$. In our research, we found P-gp to be expressed in $15.5 \%$ of patients with invasive breast cancer with lymph node metastases.

A review of the literature does not give a definite answer as to the relationship between P-gp expression and response to cancer treatment. Therefore, it is necessary to perform new research on the association between P-gp expression and other markers of breast cancer that can play a role in multidrug resistance.
Cancer hypoxia is usually associated with resistance to chemotherapy and radiation therapy, although it is not well studied in breast cancer. Ding et al. reported that P-gp expression and HIF- $1 \alpha$ expression were correlated in colon cancer samples, though these two markers were not significantly correlated with patient age or histological grade. The authors put forward a view that tumor hypoxia could be associated with resistance to chemotherapy and radiation therapy, although the relationship between the expression of P-gp and HIF-1 $\alpha$ was not elucidated [29]. Zhu et al. showed in cancer cell lines that hypoxia could be one of the causes of multidrug resistance, with a possible role for HIF-1 $\alpha$ [30]. Similar conclusions as to the relationship between hypoxia and multidrug resistance were drawn by Lv et al. [31].

We did not find P-gp to be significantly correlated with histological grade, tumor size or lymph node metastases $(p>0.05)$. Similarly, Tsukamoto et al. did not report any relationship between P-gp expression and tumor size or lymph node metastases [32], but we found a correlation between percentage of tumor cells stained for P-gp ("+", "++", “+++") and histological grade (G1-G3) ( $p=$ $0.002, r=0.687)$.

Likewise, Li et al. found no association between P-gp expression and lymph node metastases, histological type, or tumor stage [33]. We only found that P-gp was expressed most commonly in inva- 
sive breast cancers staged at pT1 and pT2, which can be explained by the fact that breast cancers whose size is estimated as less than $1 \mathrm{~cm}$ without lymph node metastasis have the most favorable prognosis, and the size of the tumor is then a very important prognostic factor [34]. But in our study, in all cases, in the tumors assessed as T1 and T2 there were present metastases to the lymph nodes, which is a negative prognostic factor, as well as the fact that these tumors were evaluated as G3, which shows their aggressiveness.

In our studies, tumors assessed as T1 and T2 most commonly demonstrated the expression of P-gp, but we did not find P-gp to be significantly correlated with tumor size. The presence of the expression of P-gp in tumors assessed as T1 and $\mathrm{T} 2$ can be explained by the presence of lymph node metastases and a high degree of histological malignancy, parameters that are regarded as the most important prognostic factors in breast cancer, and this may suggest that the presence of the expression of P-gp in these tumors may be a negative prognostic factor. This role of P-gp has been confirmed by other researchers $[5,6,14-16]$.

Moreover, we analyzed the relationship between P-gp expression and the expression of steroid receptors and HER2. P-gp expression in cancer cells or tumor blood vessels was found in $26.3 \%$ of ER+/PR+/HER2- tumors, $14.3 \%$ of ER-/ PR-/HER2-, $15.4 \%$ of ER+/PR+/HER2+ and $5.3 \%$ of ER-/PR-/HER2+ tumors.

It is known that HER2-positive breast tumors that do not express steroid receptors are less susceptible to certain forms of chemotherapy or hormonal therapy, and therefore have a worse prognosis than HER2-negative tumors. Based on previous studies, the majority of patients with HER2-positive tumors have primary multidrug resistance [35].

In our study, we found that only $9.4 \%$ of HER2-positive breast tumors expressed P-gp in cancer cells or tumor blood vessels, which might be associated with a poorer outcome due to primary resistance to treatment. The remainder of the HER2-positive tumors (90.6\%) did not express P-gp, which could suggest a better primary susceptibility to treatment. In our study, in the case of HER2-positive tumors that did not express steroid receptors (ER-/PR-/HER2+), a significant relationship with P-gp expression was found ( $p=0.049$, $r=0.105)$, but we found no correlation between HER2 positive/negative expression and P-gp ( $p=$ $0.274, r=0.050$ ).

Tsukamoto et al. and Li et al. did not find any significant relationship between the expression of P-gp and that of steroid receptors in breast cancer. However, they suggested that P-gp could be a useful predictive and prognostic marker in patients treated with chemotherapy [32, 33]. Similarly, in our research we did not find any relationship between percentage of tumor cells stained for P-gp and of steroid receptors (ER and PR) ( $p=$ $0.583, r=0.5$ ).

In our research, we found a statistically significant relationship between the expression of P-gp and that of HIF-1 $\alpha(p=0.00475, r=0.371)$ and erythropoietin (EPO) $(p<0.001, r=0.474)$ in all invasive breast cancers with lymph node metastases. There was no relationship between P-gp expression and the expression of erythropoietin receptor (EPO-R) $(p>0.05)$. In our research, in the case of P-gp-positive tumors, $55.6 \%$ of patients showed strong staining, and we found a correlation between percentage of tumor cells stained for P-gp and percentages of tumor cells stained for HIF-1 $\alpha$ $(p=0.048, r=0.273)$ and EPO $(p=0.018, r=0.60)$.

Similar results were reported by Doublier et al., who found an association between the expression of P-gp and that of HIF-1 $\alpha$. Moreover, they suggested that hypoxia is the stimulating factor for P-gp expression in breast cancer cells [36].

In conclusion, we found that HIF- $1 \alpha$ and EPO expression is significantly associated with P-gp expression in invasive breast cancer with lymph node metastases, and we found a correlation between percentage of tumor cells stained for P-gp and percentages of tumor cell stained for HIF-1 $\alpha$ and EPO. The correlation of HIF- $1 \alpha$ and P-gp expression suggests that HIF- $1 \alpha$ may be related to multidrug resistance. An important result of our study is the demonstration of a correlation between P-gp expression and patients with HER2-positive breast tumors that do not express steroid receptors, who may be less susceptible to certain forms of chemotherapy or hormonal therapy.

Despite the variety of potential methods working against the main mechanisms of multidrug resistance, attempts to limit this phenomenon to a degree allowing for effective systemic therapy of oncological diseases, including breast cancer, have been unsuccessful.

In our study, a significant correlation between P-gp expression and HIF-1 $\alpha$ expression in invasive breast cancer with metastases to the lymph nodes was found, which may suggest that expression of HIF-1 $\alpha$ in cancer cells is associated with multiple drug resistance. The results may, in the future, have significance for clinical practice, because, in order to understand the mechanisms of multidrug resistance, attention should be paid to the microenvironment of a tumor and the processes which contribute to development of cancer. One of the main such processes is hypoxia [37], and cells which are deprived of oxygen are less likely to accumulate therapeutic doses of chemotherapeutic agents [38]. Drugs that act by producing 
reactive forms of oxygen, as well as those affecting the cell cycle and drugs aiming at rapidly dividing cells, are ineffective in the case of hypoxic cells due to the reduced oxygen concentration and inhibited cell cycle [38-40]. Hypoxia is also associated with resistance to radiotherapy, because the latter is based on free radical production causing cell death [40]. Studies regarding hypoxia also indicate that it is a cause of increase in P-glycoprotein expression, which takes part in development of multidrug resistance $[38,41]$.

The clinical significance of P-glycoprotein is based on trials aiming to disable its function. Initially, first generation P-gp inhibitors were used, including verapamil, quinine and cyclosporine $A$, which had already been registered for other medical uses. Usually, those chemicals were ineffective or toxic in doses required to inhibit P-gp function. Lehnert in his studies administered epirubicin with dexverapamil to 23 patients with breast cancer, obtaining a partial response in 4 patients [42], while Belpomme et al. used verapamil administered orally with appropriate chemotherapy to 99 breast cancer patients, obtaining a higher percentage of responses to treatment (27\%), and they reported an increase in mean survival time (323 days) [43].

Second generation inhibitors, such as R-enantiomer of verapamil and the cyclosporine D analogue PSC-833 (Valspodar), also showed pharmacokinetic interactions, and, as a result, in order to prevent patient safety, it was necessary to reduce the drug dose; however, the results of such a treatment were difficult to predict due to pharmacokinetic interactions $[44,45]$. Third generation inhibitors give additional benefits including prolonged inhibition of P-glycoprotein activity in a single intravenous dose, e.g. tariquidar (XR9576) [46]. Currently used inhibitors are much better than those used in the past. They are characterized by greater substrate specificity and lower toxicity, and present better pharmacokinetic profiles. Undoubtedly, it is still necessary to search for an ideal antagonist of a transporter protein such as P-gp. An ideal agent should be administered in a non-invasive way, be effective, should not cause side effects or interact pharmacokinetically with other drugs, and it should effectively counter resistance mechanisms [47]. The search for "four generation" inhibitors is still ongoing [48].

Therefore, further research is needed regarding immunohistochemical diagnostics used for P-glycoprotein expression analysis in cancer cells and its association with other recognized markers in breast cancer, as well as new markers such as HIF$1 \alpha$, EPO, and EPO-R, but also methods of inhibition of proteins determining multidrug resistance of cancer and new methods of chemotherapy.

\section{Conflict of interest}

The authors declare no conflict of interest.

\section{References}

1. Faneyte IF, Kristel PM, Maliepaard M, et al. Expression of the breast cancer resistance protein in breast cancer. Clin Cancer Res 2002; 8: 1068-74.

2. Zhai X, Wang H, Zhu X, et al. Gene polymorphisms of $A B C$ transporters are associated with clinical outcomes in children with acute lymphoblastic leukemia. Arch Med Sci 2012; 8: 659-71.

3. Hanahan D, Weinberg RA. The hallmarks of cancer. Cell 2000; 100: 57-70.

4. Borowski E, Bontemps-Gracz M, Piwkowska A. Strategies for ovecoming $A B C$-transporters-mediated multidrug resistance (MDR) of tumor cells. Acta Biochemica Polonica 2005; 5: 609-27.

5. Ling V. Multidrug resistance: molecular mechanisms and clinical relevance. Cancer Chemother Pharmacol 1997; 40: 3-8.

6. Leonard GD, Fojo T, Bates SE. The role of ABC transporters in clinical practice. Oncolgist 2003; 8: 411-24.

7. Locher KP. Structure and mechanism of ABC transporters. Curr Opin Struct Biol 2004; 14: 426-31.

8. Gottesmann MM. Mechanisms of cancer drug resistance. Annu Rev Med 2002; 53: 615-27.

9. Gottesmann MM, Fojo T, Bates SE. Multidrug resistance in cancer: role of ATP-dependent transporters. Nat Rev Cancer 2002; 2: 48-58.

10. Parissenti AM, Gannan BR, Villeneuve DJ, Kirwan-Rhude AF, Chadderton A, Gluck S. Lack of modulation of MDR1 gene expression by dominant inhibition of CAMP-dependet protein kinase in doxorubicin-resistant MCF-7 breast cancer cells. Int J Cancer 1999; 82: 893-900.

11. Veneroni S, Zaffaroni N, Daidone MG, Benini E, Villa R, Silvestrini R. Expression of P-glycoprotein and in vitro or in vivo resistance to doxorubicin and cisplatin in breast and ovarian cancers. Eur J Cancer 1994; 30A: 1002-7.

12. Xia Z, Zhu Z, Zhang L, et al. Specific reversal of MDR1/ P-gp-dependent multidrug resistance by RNA interference in colon cancer cells. Oncol Rep 2008; 20: 1433-9.

13. Zhang Y, Ski Y, Li X, et al. Proteasome inhibitor MG 132 reverses multidrug resistance of gastric cancer through enhancing apoptosis and inhibiting P-gp. Cancer Biol Ther 2008; 7: 540-6.

14. Gruber G, Greiner RH, Hlushchuk R, et al. Hypoxia-inducible factor 1 alpha in high-risk breast cancer: an independent prognostic parameter? Breast Cancer Res 2004; 6: R191-8.

15. Wang L, Li HG, Xia ZS. Prognostic significance of erythropoietin and erythropoietin receptor in gastric adenocarcinoma. World J Gastroentero 2011; 17: 3933-40.

16. Silov G, Erdoğan Z, Özdal A, et al. The value of Tc-99m tetrofosmin scintimammography in the assessment of P-glycoprotein in patients with breast cancer. Hell J Nucl Med 2013; 16: 218-22.

17. Young LC, Campling BG, Voskoglou-Nomikos T, Cole SP, Deeley RG, Gerlach JH. Expression of multidrug resistance protein-related genes in lung cancer: correlation with drug response. Clin Cancer Res 1999; 5: 673-80.

18. Galimberti S, Marchetti A, Buttitta F, et al. Multidrug resistance related genes and $\mathrm{p} 53$ expression in human non small cell lung cancer. Anticancer Res 1998; 18: 2973-6. 
19. Clifford SC, Neal DE, Lunec J. High level expression of themultidrug resistance (MDR1) gene in the normal bladder urothelium: a potential involvement in protection against carcinogens? Carcinogenesis 1996; 17: 601-4.

20. Nakagawa M, Emoto A, Nasu $N$, et al. Clinical significance of multi-drug resistance associated protein and P-glycoprotein in patients with bladder cancer. J Urol 1997; 157: 1260-4.

21. Park J, Shinohara N, Liebert M, Noto L, Flint A, Grossman HB. P-glycoprotein expression in bladder cancer. J Urol 1994; 151: 43-6.

22. Joly F, Mangioni C, Nicoletto $M$. A phase 3 study of PSC 833 in combination with paclitaxel and carboplatin (PC-PSC) versus paclitaxel and carboplatin (PC) alone in patients with stage IV or suboptimally debulked stage III epithelial ovarian cancer or primary cancer of the peritoneum. Proc Am Soc Clin Oncol 2002; 21: 202a.

23. Burger H, Foekens JA, Look MP, et al. RNA expression of breast cancer resistance protein, lung resistance-related protein, multidrug resistance-associated proteins 1 and 2, and multidrug resistance gene 1 in breast cancer: correlation with chemotherapeutic response. Clin Cancer Res 2003; 9: 827-36.

24. Turkina AG, Logacheva NP, Stromskaya TP, et al. Studies of some mechanisms of drug resistance in chronic myeloid leukemia (CML). Adv Exp Med Biol 1999; 457: 477-88.

25. Trock BJ, Leonessa F. Clarke R. Multidrug resistance in breast cancer: a meta-analysis MDR1/gp170 expression and its possible functional significance. J Natl Cancer Inst 1997; 89: 917-31.

26. Decker DA, Morris LW, Levine AJ, Pettinga JE, Grudzien JL, Farkas DH. Immunohistochemical analysis of P-glycoprotein expression in breast cancer: clinical correlations. Ann Clin Lab Sci 1995; 25: 52-9.

27. Chung HC, Rha SY, Kim JH, et al. P-glycoprotein: the intermediate end point of drug response to induction chemotherapy in locally advanced breast cancer. Breast Cancer Res Treat 1997; 42: 65-72.

28. Chevillard S, Pouillart P, Beldjord C, et al. Sequential assessment of multidrug resistance phenotype and measurement of S-phase fraction as predictive markers of breast cancer response to neoadjuvant chemotherapy. Cancer 1996; 77: 292-300.

29. Ding Z, Yang L, Xie X, et al. Expression and significance of hypoxia-inducible factor-1 alpha and MDR1/P-glycoprotein in human colon carcinoma tissue and cells. J Cancer Res Clin Oncol 2010; 136: 1697-707.

30. Zhu H, Chen XP, Luo SF, Guan J, Zhang WG, Zhang BX. Involvement of hypoxia-inducible factor-1 alpha in multidrug resistance induced by hypoxia in HepG2 cells. J Exp Clin Cancer Res 2005; 24: 565-74.

31. Lv Y, Zhao S, Han J, Zheng L, Yang Z, Zhao L. Hypoxia-inducible factor-1alpha induces multidrug resistance protein in colon cancer. Onco Targets Ther 2015; 8: 1941-8.

32. Tsukamoto F, Shiba E, Taguchi T, et al. Immunohistochemical detection of P-glycoprotein in breast cancer and its significance as a prognostic factor. Breast Cancer 1997; 4: 259-63.

33. Li EX, Li R, Zhang ZH, Wang JB. Clinical significance of P-glycoprotein expression in breast cancer. Chin J Cancer Res 1999; 11: 218-20.

34. Leong AS, Raymond WA. Prognostic parameters in breast cancer. Pathology 1989; 21: 169-75.

35. Tang Y, Wang Y, Deosarkar S, Soroush F, Kiani MF, Wang B. Fast, stable induction of P-glycoprotein-mediat- ed drug resistance in BT-474 breast cancer cells by stable transfection of ABCB1 gene. Anticancer Res 2015 35: 2531-8.

36. Doublier S, Belisario DC, Polimeni M, et al. HIF-1 activation induces doxorubicin resistance in MCF7 3-D spheroids via P-glycoprotein expression: a potential model of the chemo-resistance of invasive micropapillary carcinoma of the breast. BMC Cancer 20124; 12: 4.

37. Nelson DA, Tan TT, Rabson AB, Anderson D, Degen hardt K, White E. Hypoxia and defective apoptosis drive genomic instability and tumorogenesis. Genes Development 2004; 18: 2095-107.

38. Comerford KM, Wallace TJ, Karhausen J, Louis NA, Mon talto SP, Colgan SP. Hypoxia-inducible factor-1-dependent regulation of the multidrug resistance (MDR1) gene. Cancer Res 2002; 62: 3387-94.

39. Tredan O, Galmarini CM, Patel K, Tannock IF. Drug resistance and the solid tumor microenvironment. J Natl Cancer Inst 2007; 99: 1441-54.

40. Kizaka-Kondoh S, Inoue M, Harada H, Hiraoka M. Tumor hypoxia: a target for selective cancer therapy. Cancer Sci 2003; 94: 1021-8.

41. Shannon AM, Bouchier-Hayes DJ, Condron CM, Toomey D. Tumour hypoxia, chemotherapeutic resistance and hypoxia-related therapies. Cancer Treat Rev 2003; 29: 297-307.

42. Lehnert M. Chemotherapy resistance in breast cancer. Anticancer Res 1998; 18: 2225-6.

43. Belpomme D, Gauthier S, Pujade-Lauraine E, et al. Verapamil increases the survival of patients with anthracycline-resistant metastatic breast carcinoma. Ann Oncol 2000; 11: 1471-6.

44. Baer MR. Phase 3 study of the multidrug resistance modulator PSC-833 in previously untreated patients 60 years of age and older with acute myeloid leukemia: Cancer and Leukemia Group B Study 9720. Blood 2002; 100: $1224-32$

45. Kolitz JE. Dose escalation studies of cytarabine, dauno rubicin, and etoposide with and without multidrug resistance modulation with PSC-833 in untreated adults with acute myeloid leukemia younger than 60 years: final induction results of Cancer and Leukemia Group B Study 9621. J Clin Oncol 2004; 22: 4290-301.

46. Guns ES, Denyssevych T, Dixon R, Bally MB, Mayer L. Drug interaction studies between paclitaxel (Taxol) and OC144-093 - a new modulator of MDR in cancer chemotherapy. Eur J Drug Metabol Pharmacokinet 2002; 27: 119-26.

47. Dantzig AH, de Alwis DP, Burgess $M$. Considerations in the design and development of transport inhibitors as adjuncts to drug therapy. Adv Drug Deliv Rev 2003; 55: 133-50.

48. Zhou S, Lim LY, Chowbay B. Herbal modulation of P-glycoprotein. Drug Metabol Rev 2004; 36: 57-104. 